\title{
Lesões traumáticas do nervo óptico
}

\author{
Luiz Fernando Cannoni', Luciano Haddad', José Carlos Esteves Veiga²
}

Faculdade de Ciências Médicas da Santa Casa de São Paulo, São Paulo, SP, Brasil.

\section{RESUMO}

Objetivo: Documentar a incidência de lesões traumáticas da via óptica, assim como a etiologia traumática; correlacionar as lesões do nervo óptico com achados radiológicos (lesões cranianas e intracranianas); e estudar lesões múltiplas de nervos cranianos. Métodos: Dezoito pacientes admitidos no Serviço de Emergência da Santa Casa de Misericórdia de São Paulo com lesão traumática da via óptica foram incluídos. Os pacientes foram divididos em três grupos de acordo com o escore da Escala de Coma de Glasgow (ECG) em: trauma leve (ECG de 13 a 15), moderado (ECG de 9 a 12) e grave (ECG de 3 a 8), distribuição quanto a gênero, presença de fraturas, lesões intracranianas, fístulas liquóricas e mecanismo de trauma. Resultados: Dos 18 casos, 17 lesões ocorreram em conjunto com outros nervos cranianos e em 1 caso houve lesão exclusiva do nervo óptico. Atropelamentos, acidentes automobilísticos, motociclísticos e ferimento por projétil de arma de fogo constituíram as causas mais frequentes de lesão do nervo óptico, de forma isolada, assim como nas lesões de múltiplos nervos. Hematomas extradurais e contusões cerebrais foram as lesões intracranianas mais frequentes e, quando presentes, as fraturas cranianas localizavam-se no teto orbitário ou na região frontal. Conclusão: Neuropatia traumática do óptico deve ser pesquisada à admissão do paciente (quando possível), pois é passível de tratamento clínico (corticoides) ou cirúrgico. Achados sugestivos de neuropatia óptica traumática incluem fraturas do assoalho ou teto orbitário e traumas de alta energia cinética.

\section{PALAVRAS-CHAVE}

Traumatismos dos nervos cranianos, traumatismos craniocerebrais, traumatismos do nervo óptico.

\section{ABSTRACT}

Optic nerve traumatic lesions

Objective: To register the incidence of the traumatic lesions to the optic nerve and its etiology; to correlate these lesions to the radiological findings (cranial and intracranial) and study multiple cranial nerve lesions. Methods: Eighteen patients admitted to the Emergency Service of Santa Casa de Misericórdia de São Paulo Hospital have been studied and lesions to the optic nerves were described. The patients were divided into 3 groups according to the Glasgow Coma Scale (GCS) in: mild trauma (GCS: 13 to 15), moderate (GCS: 9 to 12) and severe (GCS: 3 to 8), gender, fractures, intracranial lesions, CSF fistulas and type of trauma. Results: Posttraumatic single nerve lesion was observed in 1 patient and in 17 patients multiple nerve lesions associated with the optic nerve lesion were documented. Running over, vehicle and motorcycle accidents and gunshot wounds were the main causes of these lesions (single nerve and multiple nerves). Extradural hematomas and cerebral contusions were the most frequent intracranial lesions. Whenever present, the cranial fractures involved the orbital roof or the frontal region. Conclusion: Traumatic optic neuropathy occurs must be searched on the patient admission (whenever it is possible), because medical or surgical treatment can be proposed. Finding signs of traumatic optic neuropathy include fractures of the roof or floor of the orbit and traumas with high kinetic energy.

\section{KEYWORDS}

Cranial nerve injuries, craniocerebral trauma, optic nerve injuries.

1 Médico-assistente da Disciplina de Neurocirurgia da Santa Casa de Misericórdia de São Paulo, São Paulo, SP, Brasil.

2 Professor adjunto e chefe da Disciplina de Neurocirurgia da Santa Casa de Misericórdia de São Paulo, São Paulo, SP, Brasil. 


\section{Introdução}

Aproximadamente, 5\% de todos os pacientes com trauma cranioencefálico (TCE) manifestarão algum tipo de lesão ao longo do trajeto da via óptica. ${ }^{1} \mathrm{~A}$ avaliação inicial na sala de trauma, muitas vezes, encontra-se prejudicada pelo fato de o paciente apresentar alteração do nível de consciência ou edema palpebral intenso, que prejudicam a avaliação oftalmológica. ${ }^{2}$

\section{Objetivos}

Os objetivos do presente trabalho foram documentar a incidência de lesões do nervo óptico associadas a TCE, correlacionar as lesões com achados radiológicos (fraturas, afundamentos e lesões intracranianas) e etiologia traumática (atropelamentos, acidentes automobilísticos etc.), relatar a distribuição de frequência das lesões isoladas e múltiplas associadas à lesão do nervo óptico, identificando quais as associações de lesões são mais frequentes, correlacionar a incidência de fístula liquórica com a presença de lesão de nervo olfatório e revisar a literatura.

\section{Casuística e método}

Estudaram-se 18 casos de lesões traumáticas de nervo óptico em pacientes atendidos no Pronto-Socorro Central da Santa Casa de Misericórdia de São Paulo, no período de junho de 2010 a dezembro de 2012, por meio de estudo prospectivo com base em protocolo próprio, previamente autorizado pelo Comitê de Ética da Instituição. Os pacientes foram subdivididos em grupos conforme os critérios a seguir: distribuição por gênero; intensidade do trauma de acordo com a Escala de Coma de Glasgow (ECG) à admissão, em trauma leve (ECG de 13 a 15), moderado (ECG de 9 a 12) e grave (ECG de 3 a 8); presença fraturas ou afundamentos cranianos; forma da lesão traumática; presença ou ausência de lesões intracranianas; presença ou ausência de fístula liquórica traumática.

O exame neurológico dos nervos cranianos foi feito na admissão, assim como durante o período de internação e no seguimento ambulatorial.

Como critérios de lesão, incluíram-se os seguintes achados para lesão do nervo óptico: diminuição da acuidade visual (cartão de Snellen) e do campo visual, diagnosticados por confrontação direta, mantendo-se a correção óptica (uso de óculos ou lentes de contato), e alterações na campimetria confirmadas pela Disciplina de Oftalmologia.

\section{Resultados}

Foram avaliados 18 pacientes com diagnóstico de lesão traumática de nervos cranianos, os quais foram distribuídos por gênero, etiologia traumática, lesão isolada ou conjunta de nervos cranianos, lesões cranianas e intracranianas e escore na Escala de Coma de Glasgow à admissão.

\section{Acuidade visual}

Dezoito pacientes apresentaram alterações de acuidade visual. Queixas de diminuição de acuidade ou ambliopia foram incluídas. Constatou-se apenas um caso $(5,56 \%)$ com lesão isolada do nervo óptico. Os 17 casos $(94,44 \%)$ restantes apresentaram lesões concomitantes a outros nervos, o que está demonstrado na tabela 1 .

\begin{tabular}{|c|c|}
\hline \multicolumn{2}{|c|}{$\begin{array}{l}\text { Tabela } 1 \text { - Distribuição de frequências das lesões } \\
\text { combinadas do nervo óptico - acuidade visual }\end{array}$} \\
\hline Nervos lesados & Número de casos \\
\hline I/II & 2 \\
\hline $\mathrm{I} / \mathrm{II} / \mathrm{V}$ & 2 \\
\hline I/II/VIII & 2 \\
\hline I/II/III/V & 2 \\
\hline I/II/III/VI/VIII & 1 \\
\hline II/III/IV & 1 \\
\hline I/II/III/V/VI/VII/VIII & 1 \\
\hline I/II/III & 1 \\
\hline $\mathrm{II} / \mathrm{II} / \mathrm{IV} / \mathrm{V} / \mathrm{VI}$ & 1 \\
\hline II/III & 1 \\
\hline II/III/V/VI/VII/VIII & 1 \\
\hline II/VII/VIII & 1 \\
\hline II/III/VI/VII/VIII & 1 \\
\hline Total & 17 casos \\
\hline \multicolumn{2}{|c|}{$\begin{array}{l}\text { I - n. olfatório; II - n. óptico; III - n. oculomotor; IV - n. troclear; V - n. trigêmeo; VI - n. } \\
\text { abducente; VII - n. facial; VIII - n. vestíbulo-coclear. }\end{array}$} \\
\hline \multicolumn{2}{|c|}{$\begin{array}{l}\text { Atropelamentos representaram as etiologias mais } \\
\text { frequentes na lesão do II nervo, seguidos pelos aciden- } \\
\text { tes motociclísticos, automobilísticos, ferimentos por } \\
\text { projétil de arma de fogo (três casos cada) e quedas de } \\
\text { altura (dois casos) (Figura } 1 \text { ). O gênero masculino foi } \\
\text { acometido em } 12 \text { casos }(66,67 \%) \text {, enquanto o feminino } \\
\text { foi acometido em seis casos }(33,33 \%) \text {. } \\
\text { As contusões cerebrais ocorreram em cinco casos, } \\
\text { enquanto os hematomas extradurais ocorreram em } \\
\text { quatro casos, seguidos de três pacientes com hemor- }\end{array}$} \\
\hline
\end{tabular}


ragia subaracnóidea traumática e dois pacientes com hematoma subdural agudo e hematoma intraparenquimatoso (Figura 2). Em dois pacientes não houve lesão intracraniana. Três pacientes apresentaram fístula liquórica nasal.

Fraturas ocorreram em 14 casos, das quais nove eram supratentoriais, quatro eram mistas e apenas uma era fratura infratentorial (Figura 3).

Sete pacientes foram admitidos com escore 15 na ECG e quatro com escore igual a 14 .

Onze pacientes mantêm escore 5 na escala de Glasgow Outcome Scale (GOS) e sete pacientes com escore 4.

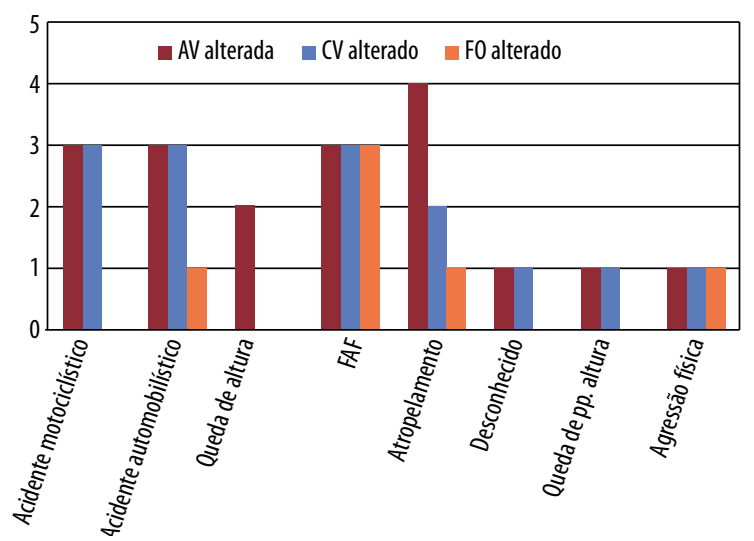

Figura 1 - Diferentes etiologias das lesões do nervo óptico. AV: acuidade visual; CV: campo visual; FO: fundo de olho; FAF: ferimento por projétil de arma de fogo.

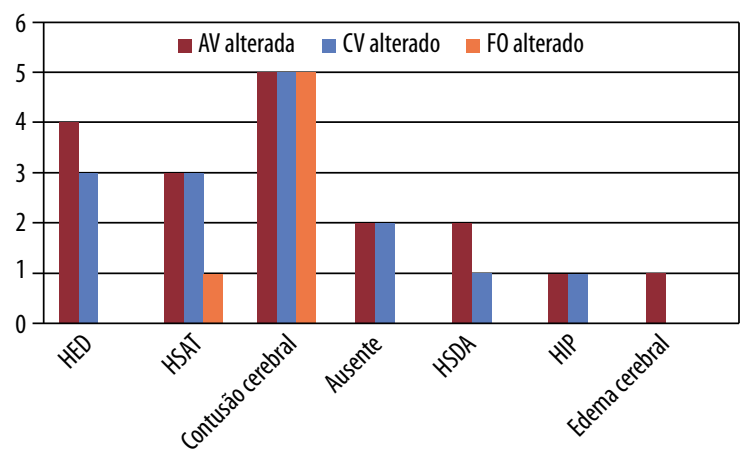

Figura 2 - Lesões intracranianas associadas à lesão do nervo óptico.

AV: acuidade visual; CV: campo visual; FO: fundo de olho; HED: hematoma extradural; HSAT: hemorragia subaracnóidea traumática; HSDA: hematoma subdural agudo; HIP: hematoma intraparenquimatoso.

\section{Campo visual}

Alterações do campo visual foram encontradas em 14 pacientes $(19,72 \%)$. A maior parte das alterações de campo visual foi gerada por acidentes motociclísticos (três casos) e automobilísticos (três casos) (Figura 1).
Fraturas de teto orbitário ocorreram em três casos, seguidos de dois casos com fratura frontal, dois casos com fratura temporal e dois casos que não evidenciaram fraturas. Três pacientes apresentaram fístula liquórica nasal.

Em termos de lesão intracraniana, as contusões cerebrais predominaram (cinco casos), seguidas pelas hemorragias subaracnóideas traumáticas (três casos), juntamente com os hematomas extradurais (três casos).

À admissão, seis pacientes apresentaram escore 15 na Escala de Coma de Glasgow e três pacientes foram admitidos com escore 14 . Na escala de resultados de Glasgow, nove pacientes mantêm escore 5 e quatro pacientes mantêm escore 4 .

\section{Fundo de olho}

Em seis pacientes $(8,45 \%)$ relatamos alteração do exame de fundo de olho (hemorragias ou edema). Três pacientes foram vítimas de ferimento por projétil de arma de fogo, que envolveu o trajeto do nervo óptico; um caso foi decorrente de acidente automobilístico; um caso foi decorrente de agressão física e outro de atropelamento (Figura 1). Não houve evidência de fístula liquórica nos pacientes com alterações do exame de fundo de olho.

Ocorreram duas fraturas frontais e cinco contusões cerebrais (Figura 2). Quatro pacientes foram admitidos com escore 15 na ECG e cinco pacientes evoluíram com escore 5 na escala resultados de Glasgow.

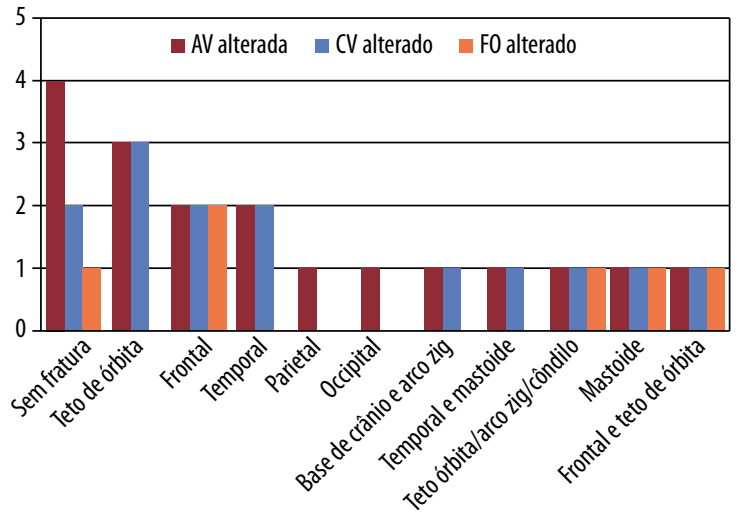

Figura 3 - Fraturas cranianas associadas à lesão do nervo óptico. AV: acuidade visual; CV: campo visual; FO: fundo de olho; arco zig: arco zigomático.

\section{Discussão}

\section{Lesão do nervo óptico}

Embora muitos traumas cranianos envolvam a região frontal e as fraturas de órbita sejam frequentes, 
lesão ocular é relativamente rara, ${ }^{3}$ o que é explicado pela proteção conferida pela órbita óssea e a relativa mobilidade do globo ocular.

Fraturas orbitárias extensas levam ao deslocamento do eixo do globo ocular e à lesão da polia do músculo oblíquo superior, causando diplopia.

Lesão traumática isolada do nervo óptico é rara. A porção intracraniana do nervo é rodeada pelo crânio e encéfalo e está protegida, exceto em traumas de alta intensidade. A porção orbitária é rodeada por osso e pela gordura periorbitária. Esta porção é relativamente móvel e capaz de ser estirada com o movimento ocular ou pela compressão do globo ocular. A porção intracanalicular do nervo é englobada por canal ósseo rígido, ao qual é parcialmente aderida.

Turner ${ }^{4}$ afirma que a lesão ocorre em 1,6\% dos casos de TCE, sendo a maior parte causada por trauma direto e de alta energia cinética à região frontal. Os sintomas iniciaram-se imediatamente ao trauma (escotomas) e a recuperação da acuidade visual ocorreu em três a quatro dias.

No presente estudo, observou-se que atropelamentos e acidentes motociclísticos (alta energia cinética) representaram a principal etiologia de lesão do II nervo.

Os escotomas são explicados por lesão da artéria central da retina e as alterações periféricas por dano a ramos nutrientes do nervo óptico. Em raros casos foram descritas fraturas que envolveram o canal óptico.

Geralmente, a perda visual é imediata e, quando tende à melhora, esta geralmente se inicia entre o terceiro ou quarto dia pós-trauma. ${ }^{4}$

Aproximadamente, $25 \%$ das lesões traumáticas em nervo óptico são causadas por traumas penetrantes, ${ }^{5}$ geralmente traduzidas por ferimentos por projéteis de arma de fogo.

Classifica-se a lesão traumática do nervo óptico em direta e indireta. A indireta resulta de trauma ipsilateral à região frontal. Forças aqui aplicadas transmitem-se ao canal óptico, local mais frequente de lesão traumática do nervo óptico. ${ }^{6} \mathrm{O}$ trauma temporal ou parietal pode ocasionalmente causar lesão em nervo óptico, mas em raríssimas ocasiões o trauma occipital é a causa. Geralmente, causa perda visual imediata e esta apresenta algum grau de recuperação em $33 \%$ dos casos. ${ }^{7}$

Analisando-se os dados, houve lesão de teto orbitário em três casos $(16,66 \%)$, seguidos por dois casos de fratura frontal $(9,99 \%)$ e dois casos $(9,99 \%)$ de fratura temporal. Em quatro casos (19,98\%) não houve associação com fratura craniana.

Contusões cerebrais e hematomas extradurais foram as lesões intracranianas predominantes. Além disso, observamos três casos com fístula liquórica nasal e seis casos com alterações do exame de fundo de olho, confirmados pela equipe de Oftalmologia.
O trauma direto aplica-se sobre o globo ocular, com avulsão do nervo óptico, associada à hemorragia retiniana. A maior parte dos pacientes sofreu trauma de crânio grave e apresenta-se inconsciente à admissão.

Cegueira unilateral é a consequência mais frequente da lesão traumática do nervo óptico, porém qualquer grau de acometimento da acuidade visual pode estar presente. Em termos de comprometimento de campo visual, os defeitos altitudinais inferiores são os mais frequentemente relatados. ${ }^{4}$

Deterioração progressiva da acuidade visual sugere processo de reversibilidade ${ }^{8}$ como hemorragia extra-axial ou compressão direta do nervo por fragmentos ósseos. Mesmo um curto período de recuperação visual após trauma craniano é, potencialmente, processo reversível. Por outro lado, perda visual imediata no impacto sugere laceração, avulsão ou contusão severa com necrose isquêmica do nervo e prognóstico muito reservado.

A tomografia de órbita fornece informações quanto à presença de fraturas do canal orbitário, assim como a presença de fragmentos ósseos em seu interior.

Em 10\% dos casos há lesões bilaterais ou lesões quiasmáticas, que geralmente são assimétricas com comprometimento unilateral severo associadas a hemianopsia temporal contralateral.

Pode haver comprometimento parcial do nervo óptico, traduzido por perda visual parcial acompanhada de hemianopsia ou visão em túnel.

A neuropatia óptica traumática é definida como a perda visual traumática que ocorre na presença de um defeito pupilar aferente sem evidência de trauma ocular ou do nervo óptico.

Embora muitos traumas de crânio envolvam a região frontal com fraturas de órbita (Figura 4), dano ao globo ocular é relativamente raro, pela própria proteção óssea da órbita e pela motilidade do globo ocular.

As lesões do globo ocular ocorrem frequentemente por trauma direto ou traumas penetrantes com consequente rotura do globo ocular. Nesses casos, geralmente o dano cerebral é mínimo com excelente prognóstico, porém o dano ao globo ocular é uma importante fonte de infecção do sistema nervoso central, ${ }^{9}$ pela presença de fístula liquórica.

Deve-se considerar também a possibilidade de sangramento no globo ocular, a qual é dividida em sangramento da câmara anterior, do vítreo e da retina. $\mathrm{O}$ sangramento retiniano é o mais frequente. É visualizado como pequena área retiniana avermelhada, edemaciada e elevada quando comparada com o nível retiniano não comprometido. Na fase crônica, o fundo de olho é visto como uma área irregular e pálida circundada por área de pigmentação enegrecida.

Quando esse tipo de lesão está localizado nas imediações da mácula, alterações da acuidade e do campo visual ocorrem. 
Deslocamento do eixo do olho ocorre durante o trauma quando a órbita é deformada por fraturas que envolvam a face ou a fronte. ${ }^{9}$ Os deslocamentos oculares mais frequentes ocorrem nas direções posteroanteriores com desvio lateral do globo ocular. Deslocamentos no eixo superior e medial são raros. Consequentemente, a diplopia é queixa comum quando os neuromecanismos oculares estão lesados. Deve-se também considerar que a polia do músculo oblíquo superior contribui para os distúrbios do movimento ocular.

Trauma direto ao nervo óptico está confinado a ferimentos por projéteis de arma de fogo no crânio e raramente é visto na prática civil.

Alterações visuais podem ser observadas (incluindo cegueira) mono ou binocularmente em TCE sem evidência direta de trauma aos nervos ópticos $(0,5 \%$ a $1,5 \%) .{ }^{10}$ A cegueira ocorre imediatamente após o trauma (geralmente monocular). Em poucos casos pode ocorrer o espasmo da artéria central da retina. Em 50\% dos casos há melhora progressiva da visão em 30 dias, sendo raros os casos que apresentam melhora após esse período. O disco óptico torna-se pálido e pode haver pigmentação enegrecida ao redor do disco. Outra hipótese é a possível presença de extravasado sanguíneo no interior da dura-máter que recobre o nervo óptico, de acordo com a descrição de Pringe ${ }^{11}$ que submeteu dois pacientes ao tratamento cirúrgico sem qualquer melhora do prognóstico.

Stephenson ${ }^{12}$ descreve sinais de comprometimento ocular sem evidência direta de trauma ocular em pacientes vítimas de TCE, como equimose conjuntival que se seguiu após trauma em região parietal; hemorragia retiniana consequente a trauma frontal; além de atrofia óptica em paciente vítima de trauma frontal.

Traquair et al. ${ }^{13}$ sugerem que a lesão ocorra nos vasos sanguíneos do nervo óptico, mais do que no nervo propriamente dito.

Deve-se atentar para a possibilidade de fraturas do canal óptico e do processo clinoide anterior, mesmo que ocorram na minoria dos casos.

O exame dos campos visuais revela diferentes tipos de achados como escotomas centrais, defeitos no campo visual periférico e hemianopsias horizontais (achado mais frequente). ${ }^{10}$

A lesão indireta do nervo óptico é definida como perda visual de origem traumática sem evidência externa ou oftalmoscópica de lesão ocular ou do nervo. ${ }^{9}$

Portanto, nesse tipo de lesão, a via óptica não é lesada por corpo estranho, mas a lesão ocorre em conjunto com o TCE fechado (0,5 a 1,5\% dos casos).

A porção intracanalicular do nervo óptico é a porção mais lesada pelo trauma craniano fechado, ${ }^{9,14}$ por ser um segmento fixo contido no interior de uma estrutura rígida e ladeado por duas estruturas com relativa mobilidade: o encéfalo e o globo ocular.
Fraturas em estruturas ósseas que englobam o nervo óptico produzem lesão em menor frequência, ${ }^{11}$ podendo envolver o canal óptico, o processo clinoide anterior e o teto orbitário. Os fragmentos ósseos levam à rotura $\mathrm{e}$ à descontinuidade das fibras do nervo óptico.

Patel et al. ${ }^{1}$ descrevem 22 lesões traumáticas de nervo óptico com $100 \%$ de presença de fraturas orbitárias
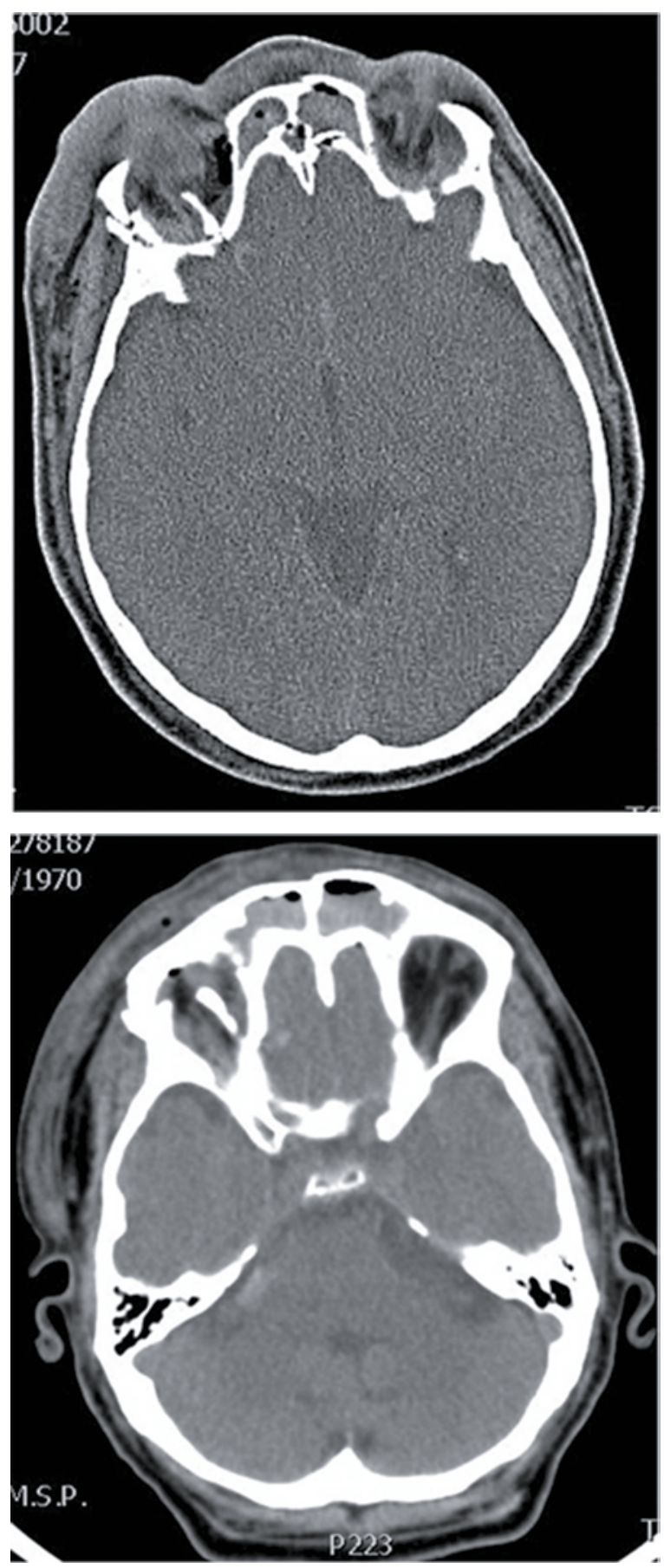

Figura 4 - Tomografia evidenciando fragmento ósseo intraorbitário direito. 
múltiplas com extensão ao ápex, além de fraturas da parede lateral da órbita, parede medial e teto da órbita.

A lesão indireta resulta de impacto ipsilateral ao crânio, geralmente na região frontal, ocasionalmente temporal e raramente occipital, e é acompanhada por perda da consciência.

A explicação mais aceita para a patogênese da lesão indireta é a insuficiência vascular. ${ }^{9}$ Se a perda visual for transitória, o vasoespasmo e a concussão do nervo podem ser as causas responsáveis, mas se a perda for permanente, provavelmente ocorre infarto do nervo óptico.

A porção intraorbitária geralmente é poupada, por causa de sua mobilidade e da proteção oferecida pela gordura periorbitária e músculos extraoculares, assim como o segmento intracraniano.

As lesões indiretas podem ser divididas em dois grupos: ${ }^{9}$ anterior e posterior.

A lesão indireta anterior denota envolvimento da porção intraocular do nervo óptico (disco óptico), a qual contém a artéria central da retina. As alterações fundoscópicas são evidentes e pode haver oclusão dessa artéria com aparecimento de edema retiniano, palidez óptica, retardo no fluxo sanguíneo retiniano em nível de disco óptico e na coroide peripapilar e mancha avermelhada na mácula, ou espasmo vascular retiniano. ${ }^{14} \mathrm{~A}$ angiografia por fluoresceína demonstra comprometimento da circulação arterial ciliar posterior na inserção escleral (o que justifica a ausência de exoftalmo), ausência de perfusão do disco óptico e extravasamento de contraste, tingindo-se o nervo óptico. Há variáveis graus de perda visual nesse tipo de lesão e o prognóstico é reservado. No nervo óptico, lacerações marginais anteriores são visualizadas e há hemorragia discal. Após duas semanas, há resolução da hemorragia, deixando uma cicatriz fortemente pigmentada nas margens do disco, e, após um mês, a palidez papilar torna-se evidente.

A lesão indireta posterior é baseada na lesão óptica sem alterações fundoscópicas durante a avaliação inicial. Após quatro a oito semanas do trauma, ocorrem palidez do disco e perda da camada de fibras nervosas retinianas. Presume-se que a lesão ocorra entre a entrada da artéria central da retina no interior do nervo óptico e o quiasma óptico. Aqui ocorrem escotomas.

Hughes ${ }^{10}$ propõe classificação das lesões de nervo óptico pela localização anatômica da lesão:

a) Lesão marginal anterior $(11,6 \%)$ - ocorre na região coroido-retiniana. Muitas vezes não visualizada na fase aguda do trauma e associada à lesão orbitária e frontal. O tipo de perda visual (descrita como em feixe de fibras) mais a palidez do disco óptico sugerem trauma na parte mais anterior do nervo óptico. Pode também haver aparência normal do fundo de olho com es- pasmo de vasos retinianos. Caracteriza-se por prognóstico muito reservado.

b) Porção anterior do nervo óptico (13\%) - lesão que ocorre posteriormente ao disco óptico, porém anteriormente à entrada da artéria central da retina. Ocorre geralmente em traumas frontais associados a fraturas. Frequentemente há palidez do disco óptico com perda total da visão na fase aguda e recuperação parcial da visão em 10\% dos casos.

c) Porção canalicular de nervo óptico (65\%) - lesões que ocorrem posteriormente à entrada da artéria central da retina ao quiasma óptico. Nessa porção, o nervo óptico está firmemente preso ao canal óptico e possui o maior trajeto, estando mais sujeito às trações pelo movimento de inércia do encéfalo. Além disso, um trauma orbitário transfere sua energia ao canal óptico. ${ }^{5}$ Em $70 \%$ dos casos ocorre por trauma frontal, ${ }^{5}$ porém somente em $10 \%$ ocorre fratura no canal óptico ou no processo clinoide anterior. Nesse tipo de lesão comumente ocorre rinorreia. A perda visual é imediata, com prognóstico reservado. Há palidez do disco óptico, podendo o restante do fundo de olho aparecer normal. Em aproximadamente $70 \%$ dos casos, o déficit do campo visual está localizado no campo inferior (hemianopsia inferior) e em $20 \%$ evidencia-se hemianopsia superior. Geralmente, a lesão do nervo óptico ocorre por estiramento vascular e trombose ou lesão de pequenos vasos que nutrem o nervo óptico. É o grupo de pacientes que costumam ser submetidos ao tratamento cirúrgico, que consiste em descompressão do nervo por remoção de espículas ósseas que o comprimem.

d) Lesão optoquiasmática (6,5\%) - ocorre lesão no ângulo quiasmático anterior ou no nervo óptico. Geralmente são traumas frontais nas proximidades da linha média. A perda visual monocular é imediata, associada à hemianopsia temporal contralateral. A anatomia do suprimento vascular do ângulo quiasmático sugere que esse tipo de trauma possa estar associado a espasmo ou trombose de um vaso específico.

e) Trauma quiasmático $(3,9 \%)$ - também ocorre por trauma frontal nas imediações da linha média com presença de fratura craniana em praticamente $100 \%$ dos casos. A perda visual é imediata com presença de hemianopsia bitemporal. Não foi relatada recuperação visual em qualquer caso. Acredita-se que o déficit visual ocorra por trombose ou vasoespasmo da artéria quiasmática central.

f) Lesão no trato óptico e corpos geniculados - lesão rara e que ocorre praticamente por projéteis 
de arma de fogo. Ocorre perda visual homônima e completa.

g) Lesão suprageniculada - ocorre nas lesões do trato genículo-calcarino e córtex calcarino. Geralmente é vista em lesões penetrantes e associa-se a fraturas ou afundamentos de crânio. Ocorre perda no campo visual congruente e homônima na periferia do campo, o que muitas vezes faz com que o indivíduo tenha uma vida normal. Porém, quando escotomas centrais ocorrem, constituem fator impeditivo às atividades de vida diária.

h) Lesão em radiações ópticas - ocorre perda visual homônima e congruente, geralmente no campo visual inferior por traumas penetrantes.

i) Trauma ao córtex calcarino - geralmente resulta de traumas não penetrantes com afundamentos cranianos localizados na linha média occipital. Ocorrem escotomas centrais, mas podem ser múltiplos ou bilaterais. É possível que a cirurgia de descompressão precoce possa melhorar o prognóstico visual.

Outra classificação é a preconizada por Walsh apud Hedges e Gragoudas, ${ }^{14}$ em que se divide a lesão traumática do nervo óptico em primária e secundária.

A lesão primária é representada por hemorragia no nervo óptico, dura-máter que o recobre ou nos espaços entre as membranas que o recobrem. Esses casos podem desenvolver atrofia óptica, mas edema no disco óptico é raramente observado. Lesões no nervo óptico ocorrem por avulsão do globo ou transecção do nervo, geralmente devidas a lesões penetrantes do nervo por corpos estranhos ou fragmentos ósseos. Lacerações marginais do disco podem estar presentes juntamente com hemorragias peripapilares. ${ }^{14}$

As lesões secundárias incluem papiledema associado a trauma cranioencefálico grave e necrose do nervo por compressão local e não perfusão de pequenos vasos ópticos centrípetos, derivados da circulação pial. Atrofia óptica secundária a glaucoma, oclusão traumática da artéria central da retina e retinopatia compressiva por pressão prolongada sobre o globo ocular também são consideradas lesões secundárias.

Não existe consenso quanto ao tratamento da lesão traumática do nervo óptico, mas é imperativo que alguma forma de tratamento seja feita no paciente que apresente sintomas de início tardio.

Rodger ${ }^{15}$ afirma que o primeiro fenômeno observável no exame de fundo de olho é a palidez do disco (total ou em parte), e a papila óptica mantém suas margens nítidas e sem alterações pigmentares retinianas.

Pacientes com perda visual imediata secundária a neuropatia óptica traumática geralmente não apresentam recuperação visual por infarto, laceração ou avulsão do nervo óptico.

\section{Avulsão do nervo óptico}

De Vries-Knoppert ${ }^{16}$ relata avulsão de nervo óptico como evento traumático raro, que pode resultar de trauma facial ou orbitário, penetrante ou não.

Salzmann ${ }^{17}$ define a avulsão como a separação do nervo óptico do globo ocular em nível da lâmina crivosa da esclera sem a rotura da bainha do nervo ou da esclera adjacente. A lâmina crivosa é uma região relativamente delicada do globo ocular, composta somente por um terço das fibras da esclera. Além disso, os axônios do nervo óptico são desmielinizados quando deixam o globo ocular, tornando-os mais vulneráveis a lesões nessa região.

O globo ocular é estirado e traciona o nervo óptico, porém o mecanismo de trauma mais frequentemente envolvido é a rotação extrema do globo ocular causada pelo deslocamento dos ossos faciais e orbitários, o que não é compartilhado por Sanborn et al., ${ }^{18}$ afirmando que na rotação extrema do globo ocular deveria ocorrer lesão concomitante da musculatura ocular extrínseca.

O diagnóstico pode não ser feito na fase aguda pela presença de hemorragia vítrea. A lesão inclui neurônios do nervo óptico, enquanto a bainha que o envolve permanece íntegra por ser mais elástica. $\mathrm{O}$ exame de fundo de olho revela lesão escurecida na região do disco óptico, rodeado por hemorragia retiniana. $\mathrm{Na}$ fase crônica a hemorragia é substituída por tecido fibroso.

Perda visual tardia também pode ocorrer e é potencialmente reversível. Ocorre por desenvolvimento de edema ou isquemia no interior do canal óptico ou compressão por hematoma subperiostal. ${ }^{4}$ Mais raramente ocorre por desenvolvimento de mucoceles ou aneurismas traumáticos.

\section{Lesões quiasmáticas}

Podem ocorrer lesões do quiasma óptico com consequente hemianopsia bitemporal simulando secção sagital do quiasma óptico, se bem que na maioria dos casos o diagnóstico possa ser apenas suspeitado. ${ }^{19}$ Acredita-se que a lesão ocorra por fenômeno trombótico, após movimento do encéfalo em relação ao crânio, ocasionando rotura de pequenos vasos piais que suprem o quiasma óptico. Existe diminuição importante da acuidade visual (hemianopsia bitemporal) associada a escotoma central.

Duke-Elder $^{20}$ afirma que a lesão pode ocorrer pelo movimento do encéfalo em relação ao crânio, provocando laceração de pequenos vasos piais que suprem o quiasma óptico.

Osterberg ${ }^{21}$ não acredita que somente as fibras que participam da formação do quiasma possuam vascularização específica, contrariando a ideia de Duke-Elder. ${ }^{20}$

Louw $^{22}$ afirma que a causa mais provável de lesão traumática em quiasma óptico seja a ocorrência de 
múltiplas lacerações das fibras nervosas que decussam com formação de hematoma.

François et al..$^{23}$ e Hughes ${ }^{24}$ realizaram estudo anatômico envolvendo a vascularização do quiasma. Não foram encontrados vasos que suprem as fibras ópticas que cruzam no quiasma óptico. A superfície inferior do quiasma é suprida pela artéria hipofisária anterossuperior. As fibras laterais (não cruzadas) são supridas por ramos diretos da carótida interna. A superfície superior recebe ramos da artéria cerebral anterior e comunicante anterior. O centro do quiasma óptico é irrigado pela artéria quiasmática, ramo da comunicante anterior.

As artérias oftálmica, coroide anterior, cerebral média e comunicante posterior estão envolvidas indiretamente na vascularização do quiasma óptico.

Para esses autores, a lesão quiasmática é causada por rotura nas fibras que decussam, com possível formação de hematomas. Lembram ainda que a artéria central da retina fornece ramos somente para a retina, e não para o nervo óptico.

O nervo óptico é suprido pela artéria central do nervo óptico, derivado da artéria oftálmica, ${ }^{23}$ e por vasos localizados na pia-máter (sistema periférico), procedentes da artéria oftálmica e das artérias ciliares.

A artéria central do nervo óptico divide-se em ramos anterior e posterior, localizados ao longo do nervo.

O sistema periférico, cujas artérias alcançam a superfície do nervo perpendicularmente e depois se dicotomizam, recebe ramos do círculo de Zinn-Haller (derivado das artérias ciliares posteriores) em nível da lâmina crivosa da esclera.

Posteriormente, nos segmentos intracanalicular e intracraniano, o nervo óptico recebe grande número de arteríolas, responsáveis pela nutrição principal do nervo ${ }^{23}$ (Figura 5).

O trato óptico é irrigado pela artéria comunicante posterior e coroide anterior, enquanto o corpo geniculado lateral recebe ramos das coroides anterior e posterior (ramos da cerebral posterior).

Para François et al., "23 "é inconcebível que o quiasma óptico, que é nutrido profusamente por 11 artérias e grande rede anastomótica de arteríolas, possa ter sua função alterada pela obstrução de uma ou mais artérias. A hemianopsia resultante deve ser atribuída à alteração capilar intratissular após compressão externa".

Osterberg ${ }^{21}$ acredita que a lesão quiasmática ocorra em sua porção medial quando causada por trauma frontal, pois os nervos ópticos são fixos no forame óptico, levando a uma rotura sagital das fibras quiasmáticas.

Traquair et al..$^{13}$ descartam a possibilidade de laceração do quiasma, pois este se localiza $1 \mathrm{~cm}$ acima da base do crânio (mesmo quiasmas pré-fixados), e a maior parte das fraturas não atinge a base do crânio, mas o trauma pode levar à laceração dos vasos que nutrem o quiasma óptico.

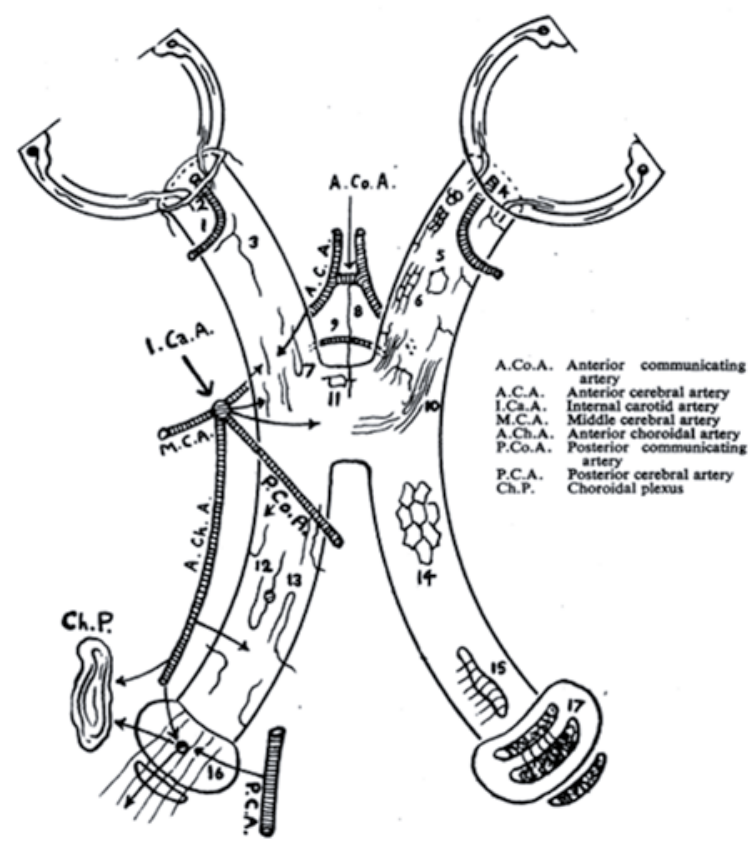

1: a. central da retina; 2: vasos colaterais da a. central da retina que suprem apenas a retina; 3: a. central do nervo óptico (rr. anterior e posterior); 4: capilares da camada fascicular da retina; 5: capilares do nervo óptico (formas pentagonais); 6: capilares do nervo óptico (formas quadradas); 7: lado nasal do segmento intracraniano do nervo óptico com capilares; 8: a. quiasmática; 9: arcada pré-quiasmática; 10: lado temporal do quiasma com capilares; 11: junção capilar da parte média do quiasma; 12: capilares do trato óptico originários das aa. perfurantes; 13: arteríolas intratissulares do trato óptico; 14: capilares do trato óptico; 15: capilares quadrangulares do trato óptico para o corpo geniculado lateral; 16: arteríolas perfurantes para o corpo geniculado lateral; 17: capilares para o corpo geniculado lateral.

Figura 5 - Vascularização das vias ópticas (François, 1958).

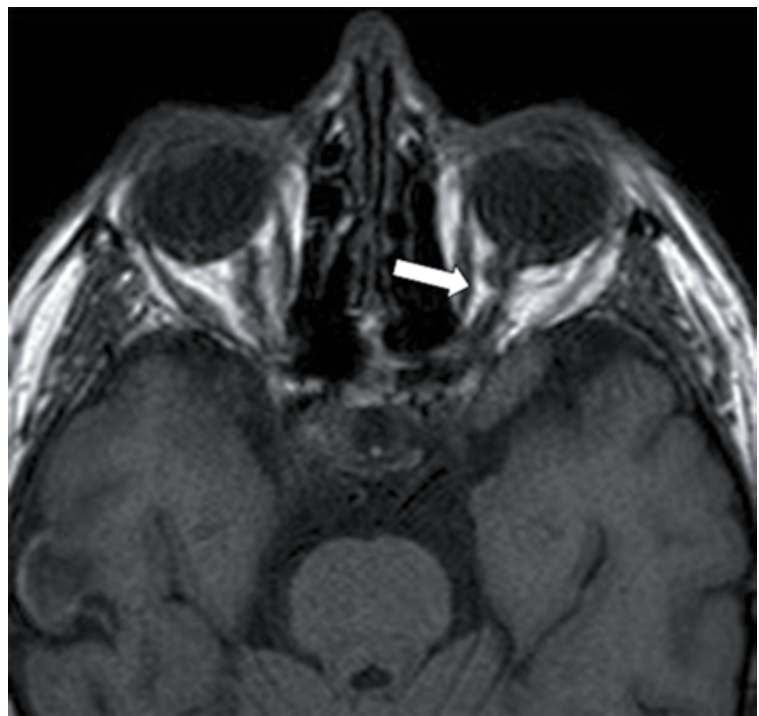

Figura 6 - Ressonância magnética evidenciando lesão do nervo óptico esquerdo.

Savino et al. ${ }^{25}$ afirmam que as principais lesões associadas à síndrome quiasmática de origem traumática são: diabetes insipidus temporária, anosmia, surdez, 
lesões associadas dos III, IV, V, VI e VII nervos, fístula liquórica, aneurisma de carótida, fístula carótido-cavernosa, meningite, pneumocrânio, pan-hipopituitarismo e hematoma intrasselar.

O TCE fechado constitui rara causa de lesão de nervo óptico (Figura 6), quando há trauma frontal de alto impacto associado a múltiplas fraturas cranianas e longo período de inconsciência. As alterações visuais variam de cegueira monocular a alterações hemianópticas bitemporais. ${ }^{25}$ No presente estudo, três casos de lesão do nervo óptico foram causados por ferimentos por projétil de arma de fogo.

Crompton ${ }^{6}$ descreve achados patológicos de etiologia traumática na via visual (da retina aos tratos ópticos) em 84 pacientes submetidos a exame de autópsia.

As principais lesões descritas foram: hemorragias $d u$ rais - sangramento em veias intradurais localizadas entre as duas camadas durais do nervo óptico; hemorragias intersticiais - ocorrem no interior do nervo óptico e nos septos fibrosos que dividem os feixes nervosos; necrose isquêmica - consiste de regiões de rarefação mielínica bem delimitadas e lesão axonal; lesões por cisalhamento - regiões pobremente definidas de rarefação mielínica e lesão axonal; hemorragias retinianas - hemorragias localizadas em qualquer das camadas da retina.

A necrose isquêmica e as lesões por cisalhamento foram as mais frequentes. $\mathrm{O}$ autor atribui isso ao fato de as fibras nervosas e vasos lesados nas duas extremidades do nervo localizarem-se nas extremidades do canal ósseo, onde o movimento dos componentes orbitários e do encéfalo fariam a lesão.

As hemorragias retinianas afetaram todas as camadas da retina e não houve relação do seu aparecimento com fraturas cranianas. As hemorragias resultam da rotura de pequenos vasos pelo impacto inicial. A hemorragia coroide pode ocorrer no impacto inicial ou ser decorrente de aumento da pressão intracraniana ou hipertensão arterial.

Gross et al. ${ }^{26}$ sugerem que o deslocamento abrupto da parede orbitária que ocorre no trauma frontal, após o cessar do mecanismo, leva a oscilações de tecidos moles, causando estiramento do canal óptico com consequente lesão da microvasculatura intraneural e das fibras nervosas.

Pringe ${ }^{11}$ discute se a presença de sangue na bainha do nervo óptico pode produzir qualquer alteração da acuidade visual.

Rowbotham $^{27}$ afirma que $50 \%$ dos pacientes com neuropatia óptica traumática não recuperarão a função visual. Para esse autor, as hemianopsias horizontais são os defeitos visuais pós-traumáticos mais comuns, atribuindo-se à hemorragia retiniana nas imediações da mácula a principal causa da perda visual. Descreve ainda lesões da porção anterior do nervo óptico, entre o disco e a entrada da artéria central da retina. Lesão ao trato óptico seria decorrente apenas de traumas penetrantes.
Kline et al. ${ }^{9}$ afirmam que não há necessidade de tratamento cirúrgico quando a perda visual é total, porém quando for progressiva, por meio de observações sequenciais, preconiza a exploração e a descompressão do nervo óptico.

$\mathrm{Na}$ casuística de Lessell, ${ }^{8}$ os acidentes com bicicleta representaram a etiologia traumática mais comum para a lesão indireta do nervo óptico. As alterações da acuidade visual não corresponderam às alterações do nível de consciência pós-traumático ou com a presença de fraturas faciais. Onze pacientes apresentaram escore 14 ou 15 ao exame neurológico de admissão.

A tríade de Maurer (TCE, epistaxe por rotura de peseudoaneurisma da artéria carótida interna e cegueira unilateral) deve alertar para lesão traumática de nervo óptico. ${ }^{1}$ A pupila de Marcus-Gunn pode estar presente em pacientes com lesão traumática de nervo óptico (estímulo luminoso provoca miose no lado não afetado e midríase no lado acometido pela lesão do nervo).

Segundo Louw, ${ }^{22}$ o quiasma óptico pode ser lesado somente por traumas de alta energia cinética, e o deslocamento ósseo nem sempre é a causa da lesão.

A lesão das fibras que decussam ocorre em nível microscópico, podendo haver diminuição da acuidade visual sem que haja alterações maculares, por possuírem fibras que decussam e fibras que não decussam no quiasma óptico.

Anderson et al. ${ }^{28}$ e Wuest ${ }^{19}$ afirmam que a secção quiasmática completa pós-traumática é rara e se deve à laceração de fibras que cruzam o plano sagital mediano, apesar de não desconsiderar outros mecanismos de lesão quiasmática como: interrupção do fornecimento sanguíneo arterial ao quiasma, hemorragia no interior das fibras que compõem o quiasma, pressão sobre o quiasma proveniente de hematoma intrasselar.

Logan e Gordon, ${ }^{29}$ por meio de observação intraoperatória de paciente com lesão traumática de quiasma óptico, afirmam que a lesão ocorreu por estiramento do quiasma pelo deslocamento do nervo óptico esquerdo. Não descreveram hematomas ou aparentes lesões macroscópicas no quiasma óptico.

Wyllie et al. ${ }^{30}$ afirmam que a lesão da via visual decorrente de trauma frontal ocorre por isquemia devida à obstrução das artérias ciliares posteriores.

Freiwald ${ }^{31}$ afirma que lesão penetrante em órbita pode levar à rotura do globo ocular com expulsão dos componentes oculares, avulsão do nervo óptico, descolamento de retina e trauma muscular suficiente para causar diplopia permanente, fratura da parede orbitária com comunicação aos seios nasais e fístula liquórica.

Ramsay ${ }^{32}$ afirma que a tomografia computadorizada, muitas vezes, não é capaz de identificar o traço de fratura que envolve o canal óptico, mesmo conhecendo o local e a direção de propagação da lesão. Portanto, aponta uma causa vascular. 
Sautter ${ }^{33}$ descreve lesões traumáticas de nervo óptico que variaram de hemorragias no interior do nervo e de sua bainha e edema do nervo a necrose, associada a contusão e infarto. Acredita que a contusão resulte de forças de tração aplicadas sobre o nervo associadas a necrose secundária por lesão em pequenos vasos nutrientes na porção canalicular e intracraniana do nervo, reafirmando o posicionamento de Hughes,$^{10}$ que afirma que as hemianopsias altitudinais sejam decorrentes de lesão vascular do nervo óptico.

\section{Conclusões}

As lesões traumáticas do nervo óptico geralmente estão associadas a etiologias de alta energia cinética. Para o seu diagnóstico, existe a necessidade de colaboração do paciente, ou seja, preservação do nível de consciência.

Devem ser suspeitadas na presença de trauma ou fratura orbitária, porém a lesão também ocorre na ausência de fraturas cranianas.

Na suspeita de lesão traumática do nervo óptico, deve-se atentar para fraturas que envolvam o canal óptico e que sejam passíveis de tratamento conservador ou cirúrgico.

\section{Conflito de interesses}

Os autores declaram não haver conflito de interesses na realização deste trabalho.

\section{Referências}

1. Patel P, Kalyanaraman $S$, Reginald $J$, Natarajan $P$, Ganapathy K, Suresh Bapu KR, et al. Post-traumatic cranial nerve injury. Indian J Neurotrauma. 2005;2:27-32.

2. Gjerris F. Traumatic lesions of the visual pathways. In: Vinken PJ, Bruyn CW, editors. Handbook of clinical neurology. Amsterdam: North-Holland Publishing; 1976. p. 27-57.

3. Hughes B. The results of injury to special parts of the brain and skull: the cranial nerves. In: Rowbotham GF, editor. Acute injuries of the head. Baltimore: Williams \& Wilkins; 1964. p. 408-10.

4. Turner JW. Indirect injuries of the optic nerve. Brain. 1943;66:140-51.

5. Lewin W. Cerebrospinal fluid rhinorrhoea in closed head injuries. Br J Surg. 1954;42(171):1-18.

6. Crompton MR. Visual lesions in closed head injury. Brain. 1970;93(4):785-92.

7. Russell WR, Schiller F. Crushing injuries to the skull; clinical and experimental observations. J Neurol Neurosurg Psychiatry. 1949;12(1):52-60.

8. Lessell S. Indirect optic nerve trauma. Arch Ophthalmol. 1989;107(3):382-6.
9. Kline LB, Morawetz RB, Swaid SN. Indirect injury of the optic nerve. Neurosurgery. 1984;14(6):756-64.

10. Hughes B. Indirect injury of the optic nerves and chiasma. Bull Johns Hopkins Hosp. 1962;111:98-126.

11. Pringe JH. Monocular blindness following diffused violence to the skull. Br J Surg. 1916;4:373.

12. Stephenson $\mathrm{S}$. Eye symptoms as the only indication of fractured base of the skull. Br J Ophthalmol. 1919;3(11):505-9.

13. Traquair HM, Dott NM, Rissell WR. Traumatic lesions of the optic chiasma. Brain. 1935;58:398-411.

14. Hedges TR 3rd, Gragoudas ES. Traumatic anterior ischemic optic neuropathy. Ann Ophthalmol. 1981;13(5):625-8.

15. Rodger FC. Unilateral involvement of the optic nerve in head injuries. Br J Ophthalmol. 1943;27(1):23-33.

16. De Vries-Knoppert WA. Evulsion of the optic nerve. Doc Ophthalmol. 1989;72(3-4):241-5.

17. Salzmann M. Die Ausreissung des Sehnerven (Evulsio nervi optici). Zeitschr für Augenh. 1903;9:489-505.

18. Sanborn GE, Gonder JR, Goldberg RE, Benson WE, Kessler $\mathrm{S}$. Evulsion of the optic nerve: a clinicopathological study. Can J Ophthalmol. 1984;19(1):10-6.

19. Wuest FC. Bitemporal hemianopsia following a traumatic lesion of the optic chiasm. Arch Ophthalmol. 1960;63:721-3.

20. Duke-Elder S, editor. System of ophthalmology. St Louis: Mosby; 1972.

21. Osterberg G. Traumatic bitemporal hemianoapsia (sagittal tearing of the optic chiasm). Acta Ophthalmol. 1938;16(4):466-74.

22. Louw JG. Traumatic bisection of the optic chiasma. S Afr Med J. 1954;28(46):971-5.

23. François J, Neetens A, Collette JM. Vascularization of the primary optic pathways. Br J Ophthalmol. 1958;42(2):65-80.

24. Hughes B. Blood supply of the optic nerves and chiasma and its clinical significance. Br J Ophthalmol. 1958;42(2):106-25.

25. Savino PJ, Glaser JS, Schatz NJ. Traumatic chiasmal syndrome. Neurology. 1980;30(9):963-70.

26. Gross CE, DeKock JR, Panje WR, Hershkowitz N, Newman J. Evidence for orbital deformation that may contribute to monocular blindness following minor frontal head trauma. J Neurosurg. 1981;55(6):963-6.

27. Rowbotham GF. Acute injuries of the head. Baltimore: Williams \& Wilkins; 1964.

28. Anderson RL, Panje WR, Gross CE. Optic nerve blindness following blunt forehead trauma. Ophthalmology. 1982;89(5):445-55.

29. Logan WC, Gordon DS. Traumatic lesions of the optic chiasma. Br J Ophthalmol. 1967;51(4):258-60.

30. Wyllie AM, McLeod D, Cullen JF. Traumatic ischaemic optic neuropathy. Br J Ophthalmol. 1972;56(11):851-3.

31. Freiwald MJ. Penetrating wound of the orbit: a 31-year follow-up. Br J Ophthalmol. 1977;61(8):544-6.

32. Ramsay JH. Optic nerve injury in fracture of the canal. $\mathrm{Br}$ J Ophthalmol. 1979;63(9):607-10.

33. Sautter $\mathrm{H}$, editor. Entwicklung und Fortschritt in der Augenheilkunde dritter Fortbildungskurs der Deutschen Ophthalmologischen Gesellschaft, Hamburg 1962. Stuttgart: Ferdinand Enke; 1963.

\section{Endereço para correspondência}

Luiz Fernando Cannoni

Rua Conselheiro Cotegipe, 543, Belenzinho

03058-000 - São Paulo, SP, Brasil

Telefone: (11) 2796-7113

E-mail: luiz2603@terra.com.br 